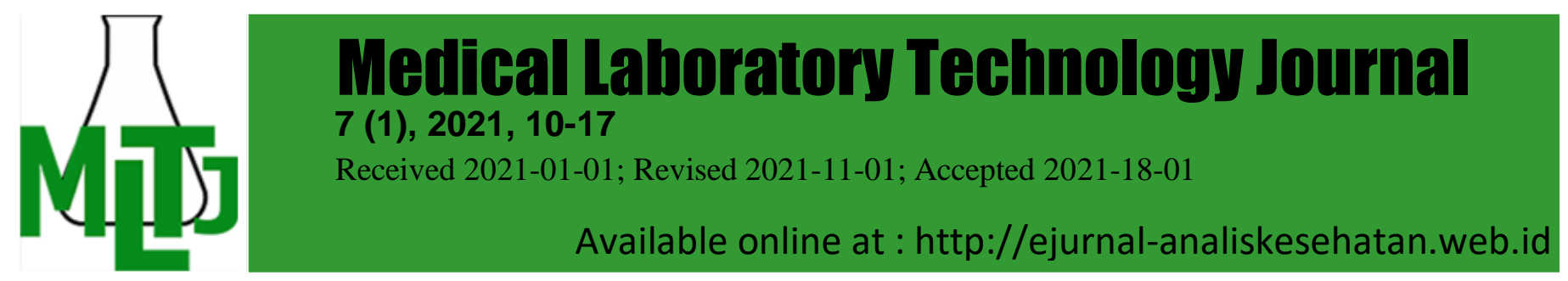

\title{
Should Ultrasonographic Giant-Cell Arteritis Signs be Detected in Patients with Polymyalgia Rheumatica?
}

\author{
*Öğr. Üyesi Fazıl Kulaklı1, Öğr. Üyesi İlker Fatih Sarı', Öğr. Üyesi Erdem Çaylı², \\ Öğr. Üyesi Nurçe Çilesizoğlu Yavuz ${ }^{1}$
}

${ }^{1}$ Giresun University Faculty of Medicine Department of Physical Medicine and Rehabilitation, Turkey. ${ }^{2}$ Giresun University Faculty of Medicine Department of Radiology, Turkey. *Email: drfzl46@gmail.com

DOI: $10.31964 / \mathrm{mltj} . v 0 \mathrm{i} 0.344$

\begin{abstract}
Assessing the presence of ultrasonographic findings of Giant-Cell Arteritis in Polymyalgia Rheumatica patients using Ultrasonography on the temporal artery. The study contributes to the literature evaluating the unclear relationship between Polymyalgia Rheumatica and Giant-Cell Arteritis. It raises awareness that Ultrasonography can be used instead of biopsy in patients with suspected Giant-Cell Arteritis. Twenty patients were newly diagnosed with Polymyalgia Rheumatica, and 20 participants as a control group were included in the study. While the Polymyalgia Rheumatica group was evaluated at baseline and sixth month, the control group was evaluated only at baseline. Laboratory, clinical and ultrasonographic findings of all participants were assessed. Gray-scale Ultrasonography and colored Doppler Ultrasonography were used to present halo and compression, occlusion, and stenosis in addition to intima-media complex thickness in bilateral temporal arteries and frontalparietal branches by an experienced radiologist blinded to the subject. No significant difference was found between Polymyalgia Rheumatica and control groups based on demographic features, clinical and ultrasonographic results at baseline and sixth month. Erythrocyte sedimentation rate of Polymyalgia Rheumatica at baseline was statistically higher than the control group. Erythrocyte sedimentation rate values have declined significantly in Polymyalgia Rheumatica patients, but no significant changes were found for clinical or ultrasonographic features during the sixth month. Ultrasonographic findings of Giant-Cell Arteritis are not present in newly diagnosed and six months followed up Polymyalgia Rheumatica patients. Further studies are needed.
\end{abstract}

Keyword: Giant cell arteritis; polymyalgia rheumatica; ultrasonography

\section{INTRODUCTION}

Polymyalgia Rheumatica (PMR) is an inflammatory disease that affects elderly patients and is characterized by morning stiffness and pain in the shoulder and pelvic area. Although the disease's exact etiology is unclear, it is thought to be based on genetic and environmental factors. There is no clearly defined test for diagnosis, and the diagnosis is made by using clinical findings and lab testing, and imaging methods. Low-to-moderate dosage corticosteroid (CS) usage is the first treatment line in those cases (Yağcı İ., 2012).

Giant-cell arteritis (GCA) is a systemic vasculitis that affects mid-to-large arteries and is also seen more frequently in elderly patients. A newly present headache in an elderly patient with rheumatic complaints might raise a GCA suspicion. In addition to headache, claudication of the jaw, problems with vision, and scalp sensitivity are also seen. Ultrasonography (US) and other imaging methods, in addition

Corresponding Author: Öğr. Üyesi Fazıl Kulaklı

Giresun University Faculty of Medicine Department of Physical Medicine and

Rehabilitation, Giresun/Turkey.

Email: drfzl46@gmail.com 
to lab tests and even temporal artery biopsy in some cases, are used for differential diagnosis (Ulusoy $\mathrm{H}$. et al., 2009). Temporal artery biopsy is not preferred due to its invasive nature and its relation with higher complication rates. The US is also told to be more cost-effective and has a higher sensitivity and specificity rate in GCA as artery biopsies only assess a specific area on a single artery (Schmidt, W.A., 2018). The treatment of choice in this condition is high-dosage corticosteroids (Ulusoy $\mathrm{H}$. et al., 2009).

PMR and GCA are thought to be two severe diseases with a close relationship with each other. It is still unclear whether PMR and GCA are two different clinical manifestations of the same disease or just a partial overlap in clinical manifestation. PMR symptoms can begin before, during, or simultaneously with GCA symptoms. A review published in 2016 reported that $40-60 \%$ of GCA patients also showed PMR signs, and about $16-21 \%$ of PMR patients showed GCA symptoms (Buttgereit F. et al., 2016). GCA usually affects temporal arteries. In patients with PMR, temporal artery biopsies might show GCA findings, yet this is an invasive intervention related to high complication rates (Nesher G., 2008). Alternatively, subclinical GCA is reported to be diagnosable using vascular imaging methods in patients with isolated PMR diagnosis; however, it is rarely done, as reported by Dejaco C et al.'s study (Dejaco C. et al., 2017). There are no previous studies in the literature that assess ultrasonographic GCA findings on PMR patients' temporal arteries. For this reason, following the recommendations previously mentioned in the literature (Schmidt W.A., 2018), we would like to evaluate the possibility of determining any ultrasonographic GCA findings on temporal arteries in PMR patients by supporting clinical and laboratory findings.

\section{MATERIALS AND METHOD \\ Patients and Image Review}

Thirty patients who were newly diagnosed with PMR using EULAR/ACR Provisional Classification Criteria for PMR (Dasgupta B. et al., 2012) were examined, and 20 patients were included in the study. Besides, 20 participants without PMR were included in the study as a control group between June 2019 - February 2020. Patients' demographics, systemic diseases, tobacco use, current medication usage, and GCA clinical manifestations were reviewed in detail. In GCA assessment, the jaw's presence of claudication, headache in the temporal region, vision problems, sensitivity and enlargement of temporal arteries, decreased or unfelt temporal artery pulse, and temporal artery murmur presence were all reviewed in the initial diagnosis and during the follow-up period. Patients with uncontrolled hypertension (4 patients), uncontrolled diabetes mellitus ( 2 patients), coronary disease ( 2 patients), and patients who smoke tobacco ( 2 patients) were excluded from the study by evaluating patient expressions and patient information on the automation system. Patients who did not use drugs regularly and did not go to regular physician control were defined as uncontrolled hypertension and uncontrolled diabetes mellitus. Patients were evaluated twice, at baseline and sixth month. While the PMR group was evaluated twice, the control group was evaluated only once. Clinical, laboratory, and ultrasonographic findings of all participants were assessed.

Informed consent was taken from all participating patients, and ethical approval for the study was obtained from the ethics committee of Giresun University (90139838000-E.28159). The study was conducted under the principles of the Declaration of Helsinki. 


\section{Ultrasonographic Evaluation}

All patients were assessed by an experienced radiologist with 15 years of experience and were blinded to their previous clinical status. The radiological assessment was done using gray-scale US and color Doppler US on temporal arteries of the patients. Toshiba Aplio 500 US device (Toshiba Medical System Corporation, Tokyo, Japan), armed with a high-frequency linear probe that supports Doppler mode usage (PLT-1005 BT [4-14 MHz]) was used for the US. Doppler frequency was set at $10 \mathrm{MHz}$, Pulse Repetition Frequency (PRF) $2-3 \mathrm{kHz}$, focus setting $5 \mathrm{~mm}$, and depth setting as $1-2 \mathrm{~cm}$. Common superficial, temporary arteries, frontal, and parietal branches are bilaterally reviewed on longitudinal and axial planes. The presence of halo sign, compression sign, occlusion, and stenosis, characteristic of GCA, was reviewed (Schmidt W.A., 2018). Also, intima-media complex measurement, which is known to give higher values in vasculitis, was done using Schäfer VS et al.'s study as reference (Schäfer VS. et al., 2017). Halo sign diameter cut-off value was set at 0.42 $\mathrm{mm}$ for typical superficial, temporary artery, $0.34 \mathrm{~mm}$ for frontal branch, and $0.29 \mathrm{~mm}$ for the parietal branch. Intima-media thickness cut-off value was set as $0.2 \mathrm{~mm}$ (Schäfer VS. et al., 2017), and mean values of bilateral temporal arteries were accepted. "Compression sign" was defined as artery not compressed when the US probe applied pressure. "Occlusion" was defined as a temporal artery filled with hypoechoic material despite PRF decrease and increased color enrichment setting and cannot show Doppler signal. Finally, "stenosis" was defined as turbulent colored pattern presence and persistent diastolic refill in pressure-wavy doppler US with increased maximum systolic flow intensity recorded as "positive" or "negative" (Schmidt W.A., 2018).

\section{Statistical Analysis}

The SPPS package program has analyzed the data for this research. Descriptive statistics have been given as averages \pm standard deviations and numbers (percent). For the comparison of independent categorical variables, Fisher's exact test is used, while McNemar's test analyzes dependent categorical variables. Normality analysis has been conducted by graphical (histogram and probability distributions) and analytical (Shapiro-Wilk test) methods. Since all the data showed normal distribution, the Student t-test was used to compare independent groups, while the paired sample t-test was used to compare dependent groups. Statistical significance level has been accepted as $p<0,05$.

\section{RESULTS AND DISCUSSION}

Our study had 40 participants in total. Twenty of them were PMR patients, while the other 20 subjects were used as the control group. The average age of the participants was $69,18 \pm 9,45$. Researchers had 32 females $(80 \%)$ and eight males $(20 \%)$. When the researcher compared the PMR group and the control group, no statistically significant differences were found based on their demographic features (age, gender, BMI) and their ultrasonographic results. However, when we compared them based on their clinical features and ESR values, we did find that the erythrocyte sedimentation rate of PMR patients was statistically higher than the control group $(p<0,001)$.

Our study had 40 participants in total. Twenty of them were PMR patients, while the other 20 subjects were used as the control group. The average age of the participants was $69,18 \pm 9,45$. Researchers had 32 females $(80 \%)$ and eight males $(20 \%)$. When the researcher compared the PMR group and the control group, no statistically significant differences were found based on their demographic features 
(age, gender, BMI) and their ultrasonographic results. However, when we compared them based on their clinical features and ESR values, we did find that the erythrocyte sedimentation rate of PMR patients was statistically higher than the control group $(p<0,001)$.

Table 1. Comparison of Demographic Features, Clinical Features, ESR, and Ultrasonographic Findings of the PMR Group at Baseline and Control Group

\begin{tabular}{|c|c|c|c|}
\hline & $\begin{array}{l}\text { PMR at Baseline } \\
(\mathrm{n}=20)\end{array}$ & $\begin{array}{l}\text { Control } \\
(\mathrm{n}=20)\end{array}$ & $\begin{array}{l}P \\
\text { value }\end{array}$ \\
\hline \multicolumn{4}{|l|}{ Demographic Features } \\
\hline Age, Years & $70,65 \pm 10,99$ & $67,70 \pm 7,62$ & 0,330 \\
\hline Gender, Female/Male & $17(85,0) / 3(15,0)$ & $15(75,0) / 5(25,0)$ & 0,695 \\
\hline $\mathrm{BMI}, \mathrm{kg} / \mathrm{m}^{2}$ & $30,41 \pm 4,07$ & $29,77 \pm 2,71$ & 0,565 \\
\hline \multicolumn{4}{|l|}{ Clinical Features } \\
\hline Jaw Claudication, n(\%) & $3(15,0)$ & $1(5,0)$ & 0,605 \\
\hline Scalp Tenderness, $\mathrm{n}(\%)$ & $3(15,0)$ & $2(10,0)$ & 1,000 \\
\hline New Onset Headache, $\mathrm{n}(\%)$ & $4(20,0)$ & $2(10,0)$ & 0,661 \\
\hline Vision Problems, $\mathrm{n}(\%)$ & $1(5,0)$ & $1(5,0)$ & 1.000 \\
\hline $\mathrm{ESR}, \mathrm{mm} / \mathrm{h}$ & $78,05 \pm 18,48$ & $28,20 \pm 12,13$ & $<0,001$ \\
\hline \multicolumn{4}{|l|}{ Ultrasonographic Findings } \\
\hline $\begin{array}{l}\text { Intima-media Thickness of } \\
\text { TA, mm }\end{array}$ & $0,153 \pm 0,028$ & $0,147 \pm 0,020$ & 0,480 \\
\hline Halo Sign & 0 & 0 & \\
\hline Compression Sign & 0 & 0 & \\
\hline Stenosis & 0 & 0 & \\
\hline Occlusion & 0 & 0 & \\
\hline
\end{tabular}

PMR: Polymyalgia Rheumatica, TA: Temporal artery ESR: Erythrocyte sedimentation rate

Table 2. Comparison of Clinical Features, ESR, and Ultrasonographic Findings of the PMR Group at the Sixth Month and Control Group

\begin{tabular}{llll}
\hline Clinical Features & $\begin{array}{l}\text { PMR at 6th } \\
\text { Month }(\mathrm{n}=20)\end{array}$ & $\begin{array}{l}\text { Control } \\
(\mathrm{n}=20)\end{array}$ & P-value \\
\hline Jaw Claudication, $\mathrm{n}(\%)$ & $2(10,0)$ & $1(5,0)$ & 1,000 \\
Scalp Tenderness, $\mathrm{n}(\%)$ & $3(15,0)$ & $2(10,0)$ & 1,000 \\
New Onset Headache, $\mathrm{n}(\%)$ & $2(10,0)$ & $2(10,0)$ & 1,000 \\
Vision Problems, $\mathrm{n}(\%)$ & $0(0,0)$ & $1(5,0)$ & 1.000 \\
\hline ESR, mm/h & $30,40 \pm 16,08$ & $28,20 \pm 12,13$ & 0,628 \\
\hline Ultrasonographic Findings & & & \\
Intima-media Thickness of TA, mm & $0,154 \pm 0,021$ & $0,147 \pm 0,020$ & 0,315 \\
Halo sign, $\mathrm{n}(\%)$ & 0 & 0 & \\
Compression Sign, $\mathrm{n}(\%)$ & 0 & 0 & \\
Stenosis, $\mathrm{n}(\%)$ & 0 & 0 & \\
Occlusion, $\mathrm{n}(\%)$ & 0 & 0 & \\
\hline PMR:Polymyalgia $\%$ & & & \\
\hline
\end{tabular}

PMR: Polymyalgia rheumatica, BMI: Body mass index, TA: Temporal artery,

ESR: Erythrocyte sedimentation rate 
Table 3. Comparison of Clinical Features, ESR, and Ultrasonographic Findings of the PMR Group at Baseline and Sixth Month

\begin{tabular}{|c|c|c|c|}
\hline \multirow{4}{*}{$\begin{array}{c}\text { Jaw Claudication at Baseline } \\
\text { Yes } \\
\text { No }\end{array}$} & \multicolumn{2}{|c|}{ Jaw Claudication at the Sixth Month } & \multirow[t]{4}{*}{$\begin{array}{l}\text { P-value } \\
1,000\end{array}$} \\
\hline & Yes & No & \\
\hline & 2 & 1 & \\
\hline & 0 & 17 & \\
\hline \multirow{4}{*}{$\begin{array}{c}\text { Scalp Tenderness at Baseline } \\
\text { Yes } \\
\text { No }\end{array}$} & \multicolumn{2}{|c|}{ Scalp Tenderness at the Sixth Month } & 1,000 \\
\hline & Yes & No & \\
\hline & 2 & 1 & \\
\hline & & 16 & \\
\hline \multirow{4}{*}{$\begin{array}{c}\text { New-onset Headache at Baseline } \\
\text { Yes } \\
\text { No }\end{array}$} & \multicolumn{2}{|c|}{$\begin{array}{l}\text { New-onset Headache During the Sixth } \\
\text { Month }\end{array}$} & 0,500 \\
\hline & Yes & No & \\
\hline & 2 & 1 & \\
\hline & 1 & 16 & \\
\hline \multirow{4}{*}{$\begin{array}{c}\text { Vision Problems at Baseline } \\
\text { Yes } \\
\text { No }\end{array}$} & \multicolumn{2}{|c|}{ Vision Problems During the Sixth Month } & 1,000 \\
\hline & & No & \\
\hline & 2 & 1 & \\
\hline & 1 & 16 & \\
\hline & $\begin{array}{l}\text { PMR at } \\
\text { baseline }\end{array}$ & $\begin{array}{l}\text { PMR at the sixth } \\
\text { month }\end{array}$ & \\
\hline $\mathrm{ESR}, \mathrm{mm} / \mathrm{h}$ & $78,05 \pm 18,48$ & $30,40 \pm 16,08$ & $<0,001$ \\
\hline Intima-media Thickness of TA, mm & $0,153 \pm 0,028$ & $0,154 \pm 0,021$ & 0,748 \\
\hline
\end{tabular}

PMR: Polymyalgia rheumatica, ESR: Erythrocyte sedimentation rate, TA: Temporal artery

In contrast, we did not find any statistically significant differences between groups based on jaw claudication, scalp tenderness, new-onset headache, and vision problems (Table 1). On the other hand, no significant differences were found between the PMR group in the sixth month and the control group based on their clinical features and ultrasonographic results (Table 2). Lastly, when we compared the clinical features, ESR, and ultrasonographic results of the PMR group at baseline and sixth month, we found that the ESR decreased statistically significantly at the 6th month according to the basal evaluation in the PMR group. In contrast, no statistically significant changes were found between groups for other clinical features (Table 3). Ultrasonographic results did not show any halo sign, compression sign, stenosis, and occlusion findings for the PMR group at baseline and sixth month.

Although previous studies in the literature reported GCA diagnosed in about 16$21 \%$ of PMR patients (Buttgereit F. et al., 2016), our study did not show any ultrasonographic or significant clinical GCA signs in any of our patients at baseline and sixth month. This means attributed to the fact that although an experienced radiologist did the assessment, the assessment was done using the US, which is a reliable method that was extensively researched yet is still debated as a form of a concrete diagnostic tool in GCA. Researchers did not perform a temporal artery biopsy in any of our patients, which is the most powerful GCA diagnosis method. This is backed up by the previous studies in the literature, which report that GCA signs can be seen in patients with PMR in temporal artery biopsy (Nesher G., 2008). Another reason is the 
relatively short follow-up period, which is six months for the study. The possibility of those patients developing GCA in the late-term will be reviewed in our routine followup. Finally, although patients were evaluated before CS usage, CS might have affected ultrasonographic imaging results in the 6th month despite low dosages.

PMR and GCA's relationship has been debated within the medical community without a clear consensus. It was previously determined that those two were different conditions even though sharing some common points, such as starting at an advanced age, seen more frequently in females, showing a systematic inflammatory response and adequate reaction to CS treatment (Gonzalez-Gay MA., 2004). As opposed to this study, GCA was defined as a vasculitis syndrome, including large artery vasculitis and PMR, in a study done in 2016 (Dejaco C. et al., 2016). Some authors argue that PMR is a mild form of GCA. A review done in 2016 reported that about $40-60 \%$ of GCA patients showed PMR findings at baseline, and $16-21 \%$ of PMR patients showed GCA symptoms (Buttgereit F. et al., 2016). Dejaco C. et al.'s study (Dejaco C. et al., 2017) reported that subclinical GCA can be diagnosed using vascular imaging methods in patients with isolated PMR diagnosis yet was seldom performed.

Additional difficulties in diagnosis include the absence of a specific lab test in both conditions and the fact that even temporal artery biopsy, which is deemed as the gold standard in diagnosis, show a positive outcome in $39-87 \%$, with even $<60 \%$ of dominant large artery GCA patients (Brack A. et al., 1999; Diamantopoulos AP. et al., 2014; Roth AM. et al.., 1984; Hall S. et al., 1983; Luqmani R. et al., 2016).

Although GCA and PMR-specific imagining techniques show a rapid progression, there is still no explicit agreement on when to use which technique. US is deemed as the primary imaging method in GCA and PMR diagnosis. Although previous critical studies reported halo sign sensitivity as $55-100 \%$ and specificity as $78-100 \%$ in the US, this imaging method still did not replace temporal artery biopsy in GCA diagnosis (Dejaco C. et al., 2017). Tabul study (Luqmani R. et al., 2016), which prospectively compared temporal artery biopsy and color doppler US, reported sensitivity as $39 \%$ to $54 \%$ and specificity as $100 \%$ to $81 \%$, respectively. There are no previous studies in the literature that assess temporal artery using US to detect GCA findings in PMR patients. However, a similar study done by Gonzales $S$ et al. (González SP. et al., 2018) reported 22 positive US results in 53 patients with suspected GCA and diagnosed 8 of those with GCA, 4 of them with PMR. However, in that study, the patients were deemed "GCA suspected," whereas in our study, despite some patients having doubtful GCA symptoms, none of them had GCA suspicion. GCA shows four characteristic pathologies in the US: the thickening of the arterial wall (halo sign), inability to compress artery (compression), stenosis, and occlusion. In GCA, cellular infiltrates, and edema can build up in intima and spread to media and adventitia surfaces.

This thickening shows a hypoechoic image around the US's artery and is defined as a "halo sign" (Schmidt WA., 1995). The previous studies defined cut-off values for halo sign diameter as $0.3-1 \mathrm{~mm}$ (Schmidt, W.A., 2018). Another recent study reported normal intima-media complex diameter as around $0.2 \mathrm{~mm}$ and can increase to $0.5-0.8 \mathrm{~mm}$ in vasculitis (Schäfer VS. et al., 2017). A key point in the assessment is the experience requirement in this field as the previous studies reported incompetence in most of the clinicians who perform US in this field (Dasgupta B. et al., 2012). Our study's radiological assessment was done by a radiologist who has remarkable experience in the temporal artery in the US to circumvent this risk. Although the idea that subclinical GCA diagnosis might be possible using vascular imaging methods in isolated PMR cases was voiced in previous studies (Dejaco C. et 
al., 2017), we could not detect any GCA findings when temporal arteries were reviewed using gray-scale and color doppler US.

Previous studies showed that the halo sign on GCA's temporal artery could disappear in 2 weeks with high-dosage CS treatment reappearing only on major relapses (Karahaliou M. et al., 2006; Habib HM. et al., 2012; De Miguel E. et al., 2012). GCA CS dosages used in the treatment are much higher than PMR dosages. The literature reports that relapses can be seen even in such high doses, and halo sign which disappeared with treatment might show up again. In our study, patients were evaluated at baseline before CS usage to prevent possible effects of CS, and no halo sign was detected. After the first evaluation, all patients administered low-dosage CS, and a halo sign was not detected in any of the patients on the 6th month. The fact that researchers were unable to clearly distinguish the reason if this is due to CS usage or that there is no halo sign which might point to a subclinical GCA in the first place can be considered as a limitation of our study. However, as mentioned above, PMR patients can develop GCA even under CS treatments. Therefore, using corticosteroids in lower dosages and the fact that PMR patients might develop GCA even under CS treatment leads us to think that the reason for not seeing halo sign in the US due to CS usage is unlikely. Our study's other limitations are the low number of patients and the limited follow-up period of 6 months.

\section{CONCLUSION}

Ultrasonographic findings of GCA are not present in newly diagnosed and six months followed up PMR patients. However, we recommend that the temporal arter US be an alternative to temporal arter biopsy as a non-invasive and effective method in patients with clinical GCA suspicion. Researchers recommend that additional studies are necessary to evaluate this subject further.

\section{CONFLICT OF INTEREST}

The authors declared no conflict of interest.

\section{REFERENCE}

Yagci, I. (2012). Polymyalgia rheumatica in 21st century/21. Yuzyilda polimyaljiya romatika. Turkish Journal of Physical Medicine and Rehabilitation, 58(2), 143151.

Ulusoy H, Sarıca N, Arslan Ş. (2009). Polymyalgia Rheumatica and Giant Cell Arteritis: A Case Report and Review of Literature. Turkish Journal of Physical Medicine and Rehabilitation, 55, 45-49.

Schmidt, W. A. (2018). Ultrasound in the diagnosis and management of giant cell arteritis. Rheumatology, 57(suppl_2), ii22-ii31.

Buttgereit, F., Dejaco, C., Matteson, E. L., \& Dasgupta, B. (2016). Polymyalgia rheumatica and giant cell arteritis: a systematic review. Jama, 315(22), 24422458.

Shoenfeld, Y., Cervera, R., \& Gershwin, M. E. (Eds.). (2010). Diagnostic criteria in autoimmune diseases. Springer Science \& Business Media.

Dejaco, C., Brouwer, E., Mason, J. C., Buttgereit, F., Matteson, E. L., \& Dasgupta, B. (2017). Giant cell arteritis and polymyalgia rheumatica: current challenges and opportunities. Nature Reviews Rheumatology, 13(10), 578.

Dasgupta, B., Cimmino, M. A., Kremers, H. M., Schmidt, W. A., Schirmer, M., Salvarani, C., ... \& Duhaut, P. (2012). 2012 provisional classification criteria for polymyalgia rheumatica: a European League Against Rheumatism/American 
College of Rheumatology collaborative initiative. Arthritis \& Rheumatism, 64(4), 943-954.

Schäfer, V. S., Juche, A., Ramiro, S., Krause, A., \& Schmidt, W. A. (2017). Ultrasound cut-off values for intima-media thickness of temporal, facial, and axillary arteries in giant cell arteritis. Rheumatology, 56(9), 1479-1483.

Gonzalez-Gay, M. A. (2004, April). Giant cell arteritis and polymyalgia rheumatica: two different but often overlapping conditions. In Seminars in arthritis and rheumatism (Vol. 33, No. 5, pp. 289-293). WB Saunders.

Dejaco, C., Duftner, C., Buttgereit, F., Matteson, E. L., \& Dasgupta, B. (2017). The spectrum of giant cell arteritis and polymyalgia rheumatica: revisiting the concept of the disease. Rheumatology, 56(4), 506-515.

Brack, A., Martinez-Taboada, V., Stanson, A., Goronzy, J. J., \& Weyand, C. M. (1999). Disease pattern in cranial and large-vessel giant cell arteritis. Arthritis \& Rheumatism: Official Journal of the American College of Rheumatology, 42(2), 311-317.

Diamantopoulos, A. P., Haugeberg, G., Hetland, H., Soldal, D. M., Bie, R., \& Myklebust, G. (2014). Diagnostic value of color Doppler ultrasonography of temporal arteries and large vessels in giant cell arteritis: a consecutive case series. Arthritis care \& research, 66(1), 113-119.

Roth, A. M., Milsow, L., \& Keltner, J. L. (1984). The ultimate diagnoses of patients undergoing temporal artery biopsies. Archives of Ophthalmology, 102(6), 901903.

Hall, S. S. J. P. L. G., Lie, J. T., Kurland, L. T., Persellin, S., O'Brien, P. C., \& Hunder, G. G. (1983). The therapeutic impact of temporal artery biopsy. The Lancet, 322(8361), 1217-1220.

Luqmani, R., Lee, E., Singh, S., Gillett, M., Schmidt, W. A., Bradburn, M., ... \& Masters, S. (2016). The role of ultrasound compared to the biopsy of temporal arteries in diagnosing and treating giant cell arteritis (TABUL): a diagnostic accuracy and cost-effectiveness study. Health Technol. Assess, 20,1-238.

Porto, S. A. G., Díaz, M. T. S., Arias, A. R., Otero, J. P., Rodríguez, A. G., Gasalla, J. V., \& de Toro Santos, F. J. (2020). A comparative study of Doppler ultrasound against temporal artery biopsy in the diagnosis of giant cell arteritis. Reumatología Clínica (English Edition), 16(5), 313-318.

Schmidt, W., Kraft, H., Völker, L., Vorpahl, K., \& Gromnica-Ihle, E. (1995). Colour Doppler sonography to diagnose temporal arteritis. The Lancet, 345(8953), 866.

Karahaliou, M., Vaiopoulos, G., Papaspyrou, S., Kanakis, M. A., Revenas, K., \& Sfikakis, P. P. (2006). Colour duplex sonography of temporal arteries before the biopsy decision: a prospective study in 55 patients with suspected giant cell arteritis. Arthritis research \& therapy, 8(4), R116.

Habib, H. M., Essa, A. A., \& Hassan, A. A. (2012). Color duplex ultrasonography of temporal arteries: role in diagnosis and follow-up of suspected cases of temporal arteritis. Clinical rheumatology, 31(2), 231-237.

De Miguel, E., Roxo, A., Castillo, C., Peiteado, D., Villalba, A., \& Martín-Mola, E. (2012). The utility and sensitivity of colour Doppler ultrasound in monitoring changes in giant cell arteritis. Clin Exp Rheumatol, 30(1 Suppl 70), S34-8. 